\title{
REFLEXÕES SOBRE O PARADIGMA HOLÍSTICO E HOLISMO E SAÚDE
}

Elizabeth Teixeira*

TEIXEIRA, E. Reflexס̃es sobre o paradigma holístico e holismo e saúde.Rev.Esc.Enf.USP, v.30, n.2, p. 286-90, ago. 1996.

Trata-se da reflexão sobre o paradigma holístico e sua constituição no âmbito das ciências. Apresenta seus princípios fundamentais e discute sua inserção na saúde. Holismo e saúde surge como desafio para o novo milênio. Destaca os eventos importantes que apontam o paradigma como novo rumo para a humanidade. Faz uma reflexão sobre suas bases, pressupostos e conceitos gerais.

UNITERMOS: Paradigma holístico, holismo e saúde.

\section{SURGE UM NOVO PARADIGMA}

O paradigma holístico emerge de uma crise da ciência, de uma crise do paradigma cartesiano-newtoniano, que postula a racionalidade, a objetividade $\mathrm{e}$ a quantificação como únicos meios de se chegar ao conhecimento. Esse paradigma busca uma nova visão, que deverá ser responsável em dissolver toda espécie de reducionismo. A holística força um novo debate no âmbito das diversas ciências e promove novas construções e atitudes.

O planeta terra está doente, seus habitantes enfermos e seu habitat poluído e contaminado. Urge uma nova atitude, novos habitantes e novos modelos de ser/fazer ciência.

As ciências da saúde não podem estar alheias a este movimento nacional e internacional. CAPRA (1986), propõe novos rumos para a saúde e aponta para o paradigma holístico. Ao propor novos caminhos para a saúde, ressalta que há que se rever os atuais modelos de serviços, de instituições de ensino e de pesquisas em saúde. A transição para o novo modelo, alerta-nos o autor, há que ser efetuada lenta e cuidadosamente, por causa do enorme poder simbólico da terapia biomédica em nossa cultura ocidental.

* Livre Docente em Enfermagem pela UNIRIO, Professor Adjunto do Departamento de Filosofia e Ciências Sociais da Universidade do Estado do Pará (UEPA), Docente do Curso de Mestrado em Enfermagem da UFPA. 
O novo paradigma força uma visão sistêmica e uma postura transdisciplinar. $O$ modelo sistêmico atende ao conceito de interdependência das partes. Postula que tudo é interdependente, que os fenômenos apenas podem ser compreendidos com a observação do contexto em que ocorre. Postula também que a vida é relação.

A postura transdisciplinar é uma atitude de encontro entre ciência e tradição, entre ciência e sabedoria. A transdisciplinaridade reata a ligação entre os ramos da ciência com os caminhos vivos de espiritualidade. O novo profissional deverá ser cientista e filósofo e o pesquisador deverá ser afoito, aberto e inclusivo, basicamente distinto do tipo clássico. CREMA (1989).

O precursor do paradigma holístico foi Jan Smuts (1870-1950). Foi o criador do termo Holismo, quando divulgou seu livro em 1926. O filósofo sustentou a existência de uma continuidade evolutiva entre matéria, vida e mente. Seu conceito avança para uma visão sintética do universo e propõe a totalidade em oposição à fragmentação.

Em 1967, Arthur Koestler desenvolve o conceito de Hólon, levando em consideração a dinâmica todo-e-partes. O antropblogo Teilhard de Chardin discute a lei da complexidade-consciência, propondo novas uniões entre partes e partículas rumo ao todo-um. O psicólogo Carl Rogers e a sua tendência realizadora do ser humano também estão em busca de um novo rumo e de um diferente modelo explicativo.

Todas as construções ocidentais, porêm, no oriente, já são antigas e estão descritas em diversos tratados tradicionais de várias das tendências orientais. Percebe-se, assim, que urge uma aproximação com tais culturas, pois estas têm bases holísticas e podem nos apontar novos rumos e novos mundos. (CREMA, 1989).

\section{PRINCÍPIOS DO PARADIGMA HOLÍSTICO}

Para o físico Brian Swimme são os seguintes os princípios do novo paradigma:

- Todos os elementos não possuem real identidade e existência fora do seu entorno total, eles interagem no universo, se envolvem e se superpõem num dinamismo de energia.

- Nossos conhecimentos são provenientes de uma participação e de uma interação no processo através de uma dimensão qualitativa da consciência.

- A análise e a síntese são fundamentais na compreensão do mundo. Para se conhecer algo há que se saber sua origem e finalidade.

- O universo é uma realidade auto-organizante, é total e inteligente. 
Para Pierre Weil a abordagem holística é como ondas a procura do mar. O autor aponta uma holologia, para tratar da dimensão do saber, e uma holopráxis, destinada a dar conta da dimensão do ser.

O parapsicólogo Stanley Krippner aponta quatro princípios básicos do paradigma holístico:

- A consciência ordinária compreende apenas uma parte pequena da atividade total do espírito humano.

- A mente humana estende-se no tempo e espaço, existindo em unidade com o mundo que ela observa.

- O potencial de criatividade e intuição são mais vastos do que ordinariamente se assume; $\mathrm{e}$

- A transcendência é valiosa e importante na experiência humana e precisa ser abrangida na comunidade orientada pelo conhecimento. (CREMA, 1989).

\section{HOLISMO E SAÚDE}

A abordagem holística em saúde convoca uma aproximação entre saber oficial e saber popular e os estudos transculturais terão enorme valia na construção de novas formas integrativas de saude. Os modelos místicos e diversas culturas tradicionais precisam ser conhecidos, estudados e integrados ao modelo holístico de saúde que se quer.

Ao longo do tempo os sistemas de saúde oscilaram entre modelos reducionistas e modelos holisticos. Dois grandes modelos vêm influenciando o pensar, fazer e viver saúde e doença. São os modelos xamanísticos e os modelos seculares.

O modelo xamanístico tem suas origens nas culturas sem escrita. Neste modelo, toda doença é conseqüência de alguma desarmonia em relação à ordem cósmica. A principal preocupação do xamanismo está relacionada com o contexto sócio-cultural em que a enfermidade ocorre.

Os modelos seculares tem sua origem nos sistemas médicos que foram organizados a partir de um conjunto de técnicas transmitidas através de textos escritos. Dois antigos sistemas médicos, um ocidental e um oriental, ilustram tais modelos. O primeiro é o sistema ocidental Hipocrático, que emergiu de uma tradição grega de cura. No âmago da medicina hipocrática as doenças são consideradas fenômenos naturais, que podem cientificamente ser estudados e influenciados por procedimentos terapêuticos e pela judiciosa conduta ou disciplina de vida de cada indivíduo.

Em oposição ao pensamento grego, os chineses não estavam muito 
interessados em relações causais, mas nos modelos sincrônicas de coisas e eventos. Esse pensamento é do tipo correlativo e dinâmico. A concepção do corpo como um sistema está bem próxima da atual abordagem holística.

A saúde para ser holística precisa ser estudada como um grande sistema, como um fenômeno multidimensional, que envolve aspectos físicos, psicológicos, sociais e culturais, todos interdependentes e não arrumados numa seqüência de passos e medidas isoladas para atender cada uma das dimensões apontadas.

É preciso um novo conceito de saúde, que a considere como equilíbrio dinâmico. Há que se rever o papel do paciente. Será preciso mostrar ao indivíduo sua possibilidade de autocura. A manutenção da saúde deverá passar a estar em lugar de destaque no novo modelo. A assistência deverá ser tanto individual como social.

Os profissionais de saúde deverão redimensionar suas práticas e relações com suas clientelas, devendo assumir a responsabilidade do equilíbrio de indivíduos e sociedades. Surge deste redimensionamento um novo assistir. A relação entre profissional de saúde e paciente será uma nova relação, cuja principal finalidade será educar o paciente acerca da natureza e do significado da enfermidade e das possibilidades de mudança do tipo de vida que o levaram à doença. (CAPRA, 1986).

Holismo e saúde provocam uma aproximação com as abordagens nãoortodoxas da saúde. Há que se encontrar as pontes necessárias para unir tais saberes. As diversas terapias e saberes reconhecem a interdependência fundamental das manifestações biologicas, físicas, mentais e emocionais do organismo, sendo, portanto, coerentes. Na valorização do corpo como um sistema, as abordagens bioenergéticas são bons exemplos.

\section{CONSTRUINDO PONTES}

A física do século XX revolucionou as bases da física clássica e trouxe uma nova visão de mundo ou cosmovisão. Física e mística se unem neste novo momento da humanidade. Ocidente e oriente se convergem em nome do holismo que se quer, que é vivo, dinâmico, interligado e sistêmico. O saber científico se aproxima do saber popular e abre-se espaço também para a sabedoria.

Em março de 1986, em Veneza, ocorreu um encontro de grandes cientistas de diversas áreas do saber e todos debateram a ciência face aos confins do conhecimento e os novos rumos para o terceiro milênio. Do evento surgiu a Declaração de Veneza, que aponta o momento de crise da ciência e indica a necessidade de reconhecermos a urgência de novos estudos e pesquisas, numa perspectiva transdisciplinar em intercâmbio dinâmico entre as ciências exatas, as ciências humanas, a arte e a tradição. O grande desafio é o compromisso social dos pesquisadores e profissionais. 
Em 1987, em Brasília, de 26 a 29 de março, ocorreu o I Congresso Holístico Internacional e I Congresso Holístico Brasileiro. Deste evento emerge a Carta de Brasília, que reafirma a relação entre o homem e o universo, entre a parte e o todo, e enfatizam as conseqüências concretas da descoberta da complementaridade entre ciências e Tradições de sabedoria. (CREMA,1989). Surgem no Brasil a Fundação Cidade da Paz e a Universidade Holística Internacional de Brasília, para atuarem na construção de pontes entre as diversas ciências e as diversas experiências.

O movimento holistico é nacional e internacional. Visa ampliar todas as comunicações entre cientistas, pesquisadores e demais interessados. A Universidade Holística de Paris, fundada em 1980, pela psic6loga MoniqueThoenig foi um marco decisivo no avanço do debate sobre o paradigma holístico.

$\mathrm{Na}$ busca de pontes, emerge a holoepistemologia, para sustentar uma evolução do saber, compatível com a do ser. Nesta nova epistemologia, há espaço para o subjetivo e o transpessoal. Pierre Weil resumiu um enunciado da moderna psicologia transpessoal na seguinte fórmula: $V R=f(E C)$, significando que a Vivência da Realidade (VR) é função (f) do Estado de Consciência (EC) no qual a pessoa se encontra no momento da observação. (CREMA,1989).

O paradigma holístico propõe um reencontro universal entre as ciências e entre estas e as Tradições de sabedoria. Com base numa visão sistêmica e numa atitude transdisciplinar, o novo paradigma começa a provocar reflexões nas diversas áreas do saber científico. Não dá mais para conviver com concepções rígidas e imutáveis. Com um pé no antigo, avançaremos para criar o novo, redescobrindo e resgatando o conteúdo da caixa preta de pandora do universo, a filosofia perene, e novamente acatando os ensinamentos do velho sábio cujo arquétipo vive em cada um de nós. (SCHABBEL, 1994).

TEIXEIRA, E. A reflection about the holistic paradigm and holistic and health. Rev.Esc.Enf.USP, v.30, n.2, p. 286-90, aug. 1996.

This article is a reflection about the holistic paradigm and their constitution in the science compass. Presents theirs fundamental principles and debates their insertion in the health. Holistic and health appear how challenge for this new period. Presents this importants events what indicate this paradigm how new course for this humanity. Presents reflection about theirs generales concepts.

UNITERMS: Holistic paradigm, holistic and health.

\section{REFERÊNCIAS BIBLIOGRÁFICAS}

1. CAPRA, Fritjof. O ponto de mutação. São Paulo, Cultrix, 1986.

2. CREMA, Roberto. Introdução à visão holística. "2 ed." São Paulo, Summus, 1989.

3. SCHABBEL, Corina. Redescobrindo... a holística. São Paulo, Iglu, 1994. 